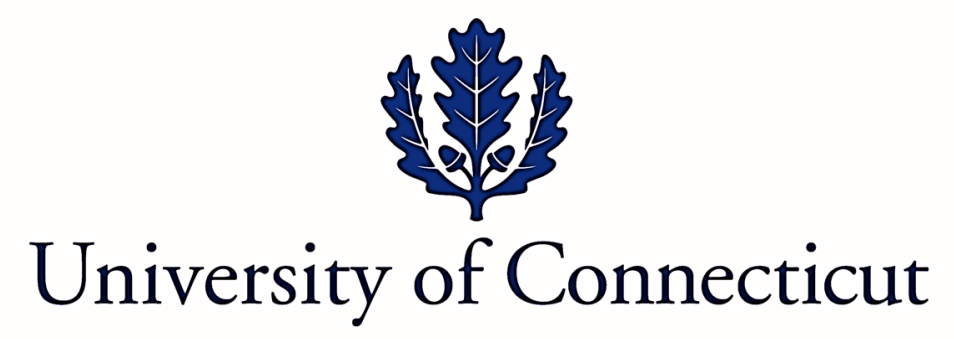

Department of Economics Working Paper Series

A Reverse Directional Distance Function to

Reconcile Between Competing Efficiency Goals:

An Application to Indian Manufacturing

by

Subhash C Ray

University of Connecticut

Kankana Mukherjee

Babson College

Working Paper 2017-08

June 2017

365 Fairfield Way, Unit 1063

Storrs, CT 06269-1063

Phone: (860) 486-3022

Fax: (860) 486-4463

http://www.econ.uconn.edu/

This working paper is indexed in RePEc, http://repec.org 


\title{
A REVERSE DIRECTIONAL DISTANCE FUNCTION TO RECONCILE BETWEEN COMPETING EFFICIENCY GOALS: AN APPLICATION TO INDIAN MANUFACTURING
}

\author{
Subhash C Ray* \\ University of Connecticut \\ Storrs CT 06269-1063 USA \\ subhash.ray@uconn.edu \\ Kankana Mukherjee \\ Babson College \\ Babson Park MA 02457 USA \\ kmukherjee@babson.edu
}

\begin{abstract}
In analysis of technical efficiency in production, either the maximum proportional increase in all outputs or a minimal proportional scaling down of all inputs is generally selected as the criterion. In the recent literature, the Directional Distance Function combines the two objectives by increasing output and reducing input simultaneously to the extent possible. This paper introduces a Reverse Directional Distance Function as one possible approach to resolve the conflict between incompatible goals through a minimal adjustment applicable to both of the two objectives. In our empirical analysis we apply the proposed method to Indian manufacturing where increasing the output and conserving energy use are both highly important objectives. A comparison of the feasible targets obtained through the conventional and the Reverse Directional Distance Functions yields an estimated tradeoff between output increase and $\mathrm{CO}_{2}$ reduction (due to energy conservation) along the frontier.
\end{abstract}

Key Words: Data Envelopment Analysis, Minimax Solution, Output Growth, Energy Saving.

JEL Classification: C61, D24, L60

*Corresponding author. 


\section{A REVERSE DIRECTIONAL DISTANCE FUNCTION TO RECONCILE BETWEEN COMPETING EFFICIENCY GOALS: AN APPLICATION TO INDIAN MANUFACTURING}

\section{Introduction}

The input-output bundle of an inefficient producer is located in the interior of the production possibility set and full efficiency is attained only when it is projected on to some point on the frontier. The problem is that, in general, the target input-output bundle located on the frontier remains arbitrary. Of course, when input and output prices are available and profit maximization is the criterion of decision making, the optimal input-output bundle on the frontier is clearly defined ${ }^{1}$. Attaining full efficiency may involve reducing inputs and increasing outputs or increasing both inputs and outputs, or reducing both inputs and outputs, as appropriate. Even when an input-output bundle is on the frontier and is technically efficient, profit maximization might require moving over to a different point on the frontier. But when prices are not available, the direction of projection of a technically inefficient bundle on to the frontier is no longer clear cut. Standard radial DEA models are either input or output-oriented. In an input-orientation, the objective is to economize on the use of inputs to the extent possible without reducing the output. By contrast, in the output orientation, one seeks to achieve the maximum expansion of the output bundle without increasing inputs.

Different variants of Graph efficiency models often target scaling up the output bundle and scaling down the input bundle simultaneously. Within a decision making unit, often there are different interest groups trying to pursue these two conflicting goals. In public sector agencies, for example, there is always a struggle between the mutually incompatible goals of expanding services and reducing expenses.. The Directional Distance Function (DDF) introduced by Chambers, Chung, and Färe (CCF) (1996) offers a compromise by setting up a target where some reduction in inputs is achieved side by side with some increase in outputs. An inefficient input-output bundle is projected in a direction chosen by the analyst until it reaches the frontier. The DDF measures the length of the possible movement in that direction and is interpreted as a measure of the inefficiency of the observed unit.

By far the most popular choice of the DDF is the maximum percentage increase in each output and decrease in each input that is simultaneously feasible within the empirically constructed production possibility set. For this, one selects the direction defined by the negative of the observed input vector

\footnotetext{
${ }^{1}$ There may, of course, be multiple bundles all of which are optimal.
} 
combined with the observed output vector. More recently, in many applications the DDF is the largest feasible amount of decrease in all inputs and increase in all outputs. The corresponding direction is the negatively sloped $45^{\circ}$ line in the northwest quadrant in the input-output space. It is clear that for both specifications, the direction of projection of an inefficient unit on to the frontier is arbitrary. Aparacio, Pastor, and Ray (APR) (2013) proposed what is described as a 'modified DDF' where the percentage reduction in inputs can be different from the percentage increase in outputs. The resulting direction of projection is derived from the optimal solution of their DEA problem and is not prespecified. In the recent literature the DDF has been extensively used in measuring efficiency and productivity change in widely different areas of empirical application ranging from pollution control vis-à-vis power generation in electric utilities to credit expansion coupled with reduction of non-performing loans in banking.

One important example of pursuing competing goals is reconciling between increasing production and reducing energy consumption in Indian manufacturing. The Indian economy has been growing at a rapid pace since liberalization. However, India's robust growth has been mostly propelled by a rapid growth of the service sector. Unlike other emerging economies where an expanding manufacturing sector has served as the engine of GDP growth, in India the share of manufacturing has stagnated at about $16 \%$ of GDP. Accelerated growth of the manufacturing sector in India remains critical for achieving the growth trajectory of the overall economy. To this end, the National Manufacturing Competitiveness Council (NMCC) has set an ambitious target for the manufacturing sector at 25\% of GDP by 2025 .

To achieve an accelerated rate of growth in the manufacturing sector, several challenges need to be met. One of them relates to the enormous energy resources that will be needed to support the high growth rate. However, the country's limited energy resources has resulted in a staggering shortage in meeting the energy demand of the overall economy. So far, the rate of growth of India's energy demand since 2000 has been slower than the rate of economic growth over the same period mainly because of the predominant role of the service sector in propelling this growth. ${ }^{2}$ However, as manufacturing comes to the forefront in the economy's growth strategy, the rate of growth in energy demand is expected to accelerate. At the same time, India is dedicated to protecting the environment and mitigating climate change. ${ }^{3}$ In 2008, India adopted the first comprehensive Integrated Energy Policy. The National Action Plan on Climate Change (NAPCC) 2008 was aimed at achieving a sustainable path to economic development while embracing environmental objectives. One of the missions of the NAPCC was the National Mission for Enhanced Energy Efficiency (NMEEE) which focused on demand-side management, to be

\footnotetext{
${ }^{2}$ India Energy Outlook, World Energy Outlook Special Report, 2015, International Energy Agency.

${ }^{3}$ See Ebinger (2016) for a discussion of the challenges involved in India's industrialization and climate change goals.
} 
implemented by the Bureau of Energy Efficiency. A flagship initiative of this mission is a market-based mechanism (Perform, Achieve, and Trade) to enhance energy efficiency in the energy intensive industries. The purpose of the policy is to establish a workable path to achieve India's growth and energy objectives (in terms of energy access, energy security and climate change), some of which are in conflict with each other.

In this study we focus on the Indian manufacturing sector over the period 2010-11 to 2013-14 and use Data Envelopment Analysis (DEA) to examine the efficiency of the 'typical' manufacturing firm across the states in India. We explicitly acknowledge the goals of (a) expanding output to achieve growth and (b) conserving energy use to release energy supply for other uses ${ }^{4}$, reduce cost of production to enhance competitiveness, and reduce emission from use of fossil fuels.

The main contributions of the paper are both methodological and empirical. In terms of the DEA methodology, we propose a Reverse Directional Distance Function approach for reconciling the two competing efficiency goals. Unlike in the conventional DDF analysis where one projects an inefficient input-output bundle lying in the interior of the production possibility set outwards to the frontier, we start from an infeasible bundle that combines technically efficient output bundle with the technically efficient input bundle and project it inwards to the frontier. The direction of ultimate outward projection of an inefficient bundle is determined by the position of the infeasible bundle. Second, and more importantly, the optimal feasible bundle represents the minimum percentage adjustment that needs to be made to the incompatible goals of the radial output oriented projection and the radial input oriented projection. This, in essence, represents a minimax solution of a goal programming problem. This approach highlights the tradeoffs involved in pursuing one goal versus the other. Our proposed DEA methodology can be applied to any decision making context using firm (or plant, or industry, or country) level data where two or more conflicting goals have to be reconciled in an optimal manner. At the same time, as an empirical application this paper adds to the sparse literature on Indian manufacturing that examines efficiency of firms under conflicting objectives. Our use of state level data enables us to understand the regional differences in manufacturing performance in terms of the two goals. It is generally recognized that due to the federal structure of policy implementation, there exists widespread differences between states in India which makes it important to look beyond national figures to fully understand the country's energy efficiency dynamics. A few papers have utilized the DDF to analyze the efficiency of Indian manufacturing firms. Mandal and Madheswaran (2010) analyzed the Indian cement industry using the traditional DDF approach for joint production of 'good' and 'bad' $\left(\mathrm{CO}_{2}\right)$ output. Mandal (2010) followed

\footnotetext{
${ }^{4}$ Note that a unit of energy saved is more than a unit of energy produced because it avoids the loss that typically occurs in the transmission and distribution process.
} 
a similar approach to analyze the Indian cement industry to examine the effects of regulation by considering different disposability assumptions for the bad output $\left(\mathrm{CO}_{2}\right)$. Mukherjee (2010) was the first study to use DDFs to obtain comprehensive measures of efficiency of firms, given the joint goals of achieving output growth and energy conservation. In contrast, the present study uses the Reverse DDF to analyze the optimal compromise between these two competing goals.

Our results show that on average across states, if output increase is the only goal, then a maximum of $4.7 \%$ increase in output is possible in 2013-14. In that same year, a maximum reduction in energy use of $20 \%$ on average is possible if that is the only goal. As mentioned earlier, these are not simultaneously achievable targets and some concession is required from both sides. After a minimum concession of $3.1 \%$ from both goals, an average increase in output of $1.6 \%$ along with an average reduction in energy use by about $16.8 \%$ is possible. In contrast, using the conventional DDF approach suggests that output increase and energy reduction would both be $4.1 \%$ (on average).

The rest of the paper unfolds as follows. Section 2 presents the conceptual background and nonparametric methodology as well as formulates the alternative DEA models. Section 3 explains the data and model construction for our empirical analysis and discusses the results. Section 4 is the conclusion.

\section{Methodology}

\subsection{The Conceptual Framework}

\subsubsection{The Production Technology}

Consider an industry producing non-negative vectors of $m$ outputs, $y \in R_{+}^{m}$ using (non-negative) vectors of $n$ inputs, $x \in R_{+}^{n}$. An input-output pair $(x, y)$ constitutes a feasible production plan if $y$ can be produced from $x$. The production possibility set consists of all feasible production plans and can be defined as

$$
T=\{(x, y): x \text { can produce } y\}
$$

In the single output case, the set $T$ is often defined using a production function as

$$
T=\{(x, y): y \leq f(x)\}
$$


In the multiple output case one may use the Transformation function $F(x, y)=k$ to define the production possibility set as

$$
T=\{(x, y): F(x, y) \leq 0\}
$$

The Graph of the technology is defined as

$$
G=\{(x, y): \beta<1 \Rightarrow(\beta x, y) \notin T ; \alpha>1 \Rightarrow(x, \alpha y) \notin T\}
$$

For a functional representation of $T$, in the single output case

$$
G=\{(x, y): y=f(x)\}
$$

Similarly, in the multiple output case,

$$
G=\{(x, y): F(x, y)=0\}
$$

\subsubsection{Shephard Distance Functions and Technical Efficiency}

When an input-output bundle $\left(x^{0}, y^{0}\right)$ is in the interior of the set $T$, there remains the possibility of expanding the output without altering the input. Alternatively, one may reduce the input without changing the output. On the other hand, if the $\left(x^{0}, y^{0}\right)$ bundle is infeasible, one needs to scale the output down or scale the input up to attain feasibility. Following Shephard (1970) one can define the Output Distance Function

$$
D^{y}\left(x^{0}, y^{0}\right)=\min \mu:\left(x^{0}, \frac{1}{\mu} y^{0}\right) \in T \text {. }
$$

As is apparent, for any feasible input-output bundle $(x, y), \mathrm{D}^{y}(x, y) \leq 1$. On the other hand, if $\mathrm{D}^{y}(x, y)>1$, the $(x, y)$ bundle is infeasible. In a parallel manner, the Input Distance Function can be defined as

$$
D^{x}\left(x^{0}, y^{0}\right)=\max \rho:\left(\frac{1}{\rho} x^{0}, y^{0}\right) \in T
$$

For any feasible input-output bundle $(x, y), D^{x}(x, y) \geq 1$. It can be seen from the definition of the Graph of the technology in (4), 


$$
(x, y) \in G \Rightarrow\left(D^{y}(x, y)=D^{x}(x, y)=1\right) .
$$

The input-oriented Farrell technical efficiency

$$
\tau_{x}\left(x^{0}, y^{0}\right)=\theta^{*}=\min \theta:\left(\theta x^{0}, y^{0}\right) \in T
$$

is the inverse of $D^{x}\left(x^{0}, y^{0}\right)$.

The output-oriented Farrell technical efficiency is

$$
\tau_{y}\left(x^{0}, y^{0}\right)=\frac{1}{\varphi^{*}}
$$

where $\varphi^{*}=\max \varphi:\left(x^{0}, \varphi y^{0}\right) \in T$. Clearly, $\tau_{y}\left(x^{0}, y^{0}\right)=D^{y}\left(x^{0}, y^{0}\right)$.

the input-oriented radial projection of $\left(x^{0}, y^{0}\right)$ onto the graph of the technology is $\left(x_{*}^{0}, y^{0}\right)=\left(\theta^{*} x^{0}, y^{0}\right)$. The corresponding output-oriented projection is $\left(x^{0}, y_{*}^{0}\right)=\left(x^{0}, \varphi^{*} y^{0}\right)$.

\subsubsection{The Directional Distance Function}

The output-oriented projection expands the output vector moving vertically towards the graph of the technology. The input-oriented projection contracts the input vector and moves horizontally to a different point on the graph. One may, however, choose a different direction as an inefficient input-output bundle is projected on to the graph of the technology. The Directional Distance Function (DDF) introduced by Chambers, Chung, and Färe (CCF)(1996) selects a direction $g=\left(g^{x}, g^{y}\right)$ and projects the observed input-output bundle $\left(x^{0}, y^{0}\right)$ onto the graph of the technology in the chosen direction. The DDF is defined as

$$
\vec{D}\left(x^{0}, y^{0} ; g^{x}, g^{y}\right)=\max \beta:\left(x^{0}+\beta g^{x}, y^{0}+\beta g^{y}\right) \in T
$$

It can be seen that for $\left(g^{x}=0, g^{y}=y^{0}\right)$ one gets the output-oriented projection and $\left(g^{x}=-x^{0}, g^{y}=0\right)$ leads to the input-oriented projection. A popular choice of the direction vector $g$ is $\left(g^{x}=-x ; g^{y}=y\right)$. The corresponding DDF is

$$
\vec{D}\left(x^{0}, y^{0} ; g^{x}=-x^{0}, g^{y}=y^{0}\right)=\max \beta:\left((1-\beta) x^{0},(1+\beta) y^{0}\right) \in T \text {. }
$$


The popularity of this projection stems from its simple intuitive interpretation. Compared to the observed bundle, the benchmark on the frontier represents a reduction in all inputs and an increase in all outputs by the same proportion, $\beta$. Another direction vector that is often chosen in applied work is $\left(g^{x}=-l ; g^{y}=\imath\right)$ , where $l$ is a vector with each element equal to unity. In this case the optimal value of $\beta$ is the largest feasible absolute amount of increase in all outputs and decrease in all inputs. Given that inputs and outputs are measured in different units, it is not clear what this $\beta$ actually measures.

The different Distance functions can be explained graphically using the 1-input 1-output example shown in Figure 1. The curve $O C$ shows the production function

$$
y=f(x)=2 \sqrt{x}
$$

The production possibility set $T=((x, y): y \leq 2 \sqrt{x})$ consists of all points on or below the curve $O C$. The point $P$ shows the input-output bundle $\left(x^{0}=9, y^{0}=4\right)$. The output-oriented projection of $P$ is the point $A,\left(x^{0}=9, \mathrm{y}_{*}^{0}=6\right)$. The input-oriented projection, on the other hand, is $B\left(x_{*}^{0}=4, y^{0}=4\right)$. Thus,

$$
\begin{aligned}
& D^{y}\left(x^{0}=9, y^{0}=4\right)=\frac{4}{6}=\frac{2}{3} \\
& \text { and } \quad D^{x}\left(x^{0}=9, y^{0}=4\right)=\frac{9}{4} .
\end{aligned}
$$

The various DDFs project the observed inefficient bundle onto some point on the $B A$ segment of the $O C$ curve depending on the direction of projection chosen. Consider the DDF defined in (13) above. The point $D$ in the northwest quadrant corresponds to the direction vector $g=\left(-x^{0}, y^{0}\right)=(-9,4)$. The point $E$ on the graph of the production function is the projection of the observed point $P$ in the direction defined by $O D$. The DDF is measured by $\beta=\frac{O F}{O D}$.

At the directional projection $E$,

$$
\begin{aligned}
& (1+\beta) y^{0}=f\left((1-\beta) x^{0}\right) \\
& \Rightarrow 4(1+\beta)=2 \sqrt{9(1-\beta)} \\
& \Rightarrow 4 \beta^{2}+17 \beta-5=0 .
\end{aligned}
$$

The positive root of this quadratic equation yields $\beta=0.27$. Thus, at the directional projection $E$, $\left(x^{*}=6.57 ; y^{*}=5.08\right)$. Note that $\beta$ is a measure of inefficiency of the observed unit. 
Next consider the alternative DDF defined in (14). This time, the direction vector is $g=(-1,1)$ shown by the point $G$ and the projection onto the graph is the point $H$. We get $\beta$ from the equation

$$
\begin{aligned}
& y^{0}+\beta=f\left(x^{0}-\beta\right)=2 \sqrt{x^{0}-\beta} \\
& \Rightarrow 4+\beta=2 \sqrt{9-\beta} \\
& \Rightarrow 16+8 \beta+\beta^{2}=36-4 \beta \\
& \Rightarrow \beta^{2}+12 \beta-20=0
\end{aligned}
$$

The positive root of the quadratic equation in (18) yields $\beta=1.483$. Thus at the optimal directional projection $H$ the input is reduced and the output is increased by 1.483 units leading to the bundle $(x=7.517 ; y=5.483)$. As noted, before, this has no simple intuitive meaning and is not a summary measure of inefficiency.

\subsubsection{A Directional Distance Function for a Minimax Projection}

Both of the DDFs as well as the output and input oriented Shephard Distance Functions have two things in common. First, the direction of projection is predetermined by the analyst. Second, the projection is from an interior (or a boundary point) of the production possibility set on to the graph. In this paper, we propose a projection of an infeasible point on to the graph. Also, the direction of projection is endogenously determined.

Consider an observed inefficient input-output bundle $\left(x^{0}, y^{0}\right)$, its output oriented projection $\left(x^{0}, \varphi^{*} y^{0}\right)$ and its input oriented projection $\left(\theta^{*} x^{0}, y^{0}\right)$. Next consider the bundle $\left(x^{*}, y^{*}\right)=\left(\theta^{*} x^{*}, \varphi^{*} y^{*}\right)$. It is not a feasible bundle because the output bundle $\varphi^{*} y^{0}$ is producible only when the input bundle $x^{0}$ is left unchanged. Similarly, the scaled down input bundle can produce the observed output $y^{0}$ but not the expanded output $\varphi^{*} y^{0}$. We, therefore, seek the minimum value of $\delta$ such that there is some feasible input-output bundle $(\bar{x}, \bar{y})$ close enough to $\left(x^{*}, y^{*}\right)$ so that $\frac{\bar{x}-x^{*}}{x^{0}} \leq \delta$ and $\frac{y^{*}-\bar{y}}{y^{0}} \leq \delta$. This amounts to finding the minimum value of $\delta$ such that $(\bar{x}, \bar{y})=\left(\left(\theta^{*}+\delta\right) x^{0},\left(\varphi^{*}-\delta\right) y^{0}\right)$ is feasible.

In Goal Programming (GP), one sets up targets which are together infeasible and then depending on the priorities of the analyst, minimizes a weighted combination of the deviations from the individual targets. In Multiple Objective Linear programming (MOLP), one selects the most preferred non-dominated 
outcome. In this paper, we use input and output oriented projections to select the targets and then determine the minimax solution

$$
\begin{aligned}
& \delta^{*}=\min \delta \\
& \text { s.t. } \quad \frac{y^{*}-y}{y^{0}} \leq \delta ; \\
& \quad \frac{x-x^{*}}{x^{0}} \leq \delta ; \\
& \quad y^{*}=\varphi^{*} y^{0} ; x^{*}=\theta^{*} x^{0} ; \\
& \quad(x, y) \in T .
\end{aligned}
$$

Alternatively,

$$
\delta^{*}=\min \delta:\left(\left(\theta^{*}+\delta\right) x^{0},\left(\varphi^{*}-\delta\right) y^{0}\right) \in T
$$

We characterize $\delta^{*}$ as a Reverse Directional Distance Function.

This reverse DDF differs from the others considered earlier above in three important respects. First, it is evaluated at a target input-output bundle and not the observed input output bundle. Second, the direction of projection is the reverse of what we find for any standard DDF in the sense that the objective is to scale the input upwards and the output downwards relative to the $\left(x^{*}, y^{*}\right)$ bundle in order to move to the graph. Finally, we seek the minimum rather than the maximum adjustment in this direction. In this case, the direction vector $g$ is $\left(g^{x}=x^{0}, g^{y}=-y^{0}\right)$ and the reverse DDF is

$$
\overleftarrow{D}\left(x^{*}, y^{*} ; g=x^{0}, g^{y}=-y^{0}\right)=\min \delta:\left(x^{*}+\delta x^{0}, y^{*}-\delta y^{0}\right) \in T .
$$

It is possible, however, to derive a conventional DDF evaluated at the observed input-output bundle $\left(x^{0}, y^{0}\right)$ and a direction of projection that leads to the bundle $(\bar{x}, \bar{y})$ on the graph. Note that

$$
\begin{aligned}
\bar{x} & =\left(\theta^{*}+\delta\right)^{*} x^{0} \\
\text { and } \quad \bar{y} & =\left(\varphi^{*}-\delta\right) y^{0} .
\end{aligned}
$$


Now define $\beta_{x}=1-\left(\theta^{*}+\delta\right)$ and $\beta_{y}=\left(\varphi^{*}-\delta\right)-1$. Then, as in Aparicio et al (2013), $\bar{x}=\left(1-\beta_{x}\right) x^{0}$ and $\bar{y}=\left(1+\beta_{y}\right) y^{0}$. Finally, define $\kappa=\frac{\beta_{x}}{\beta_{y}}$ and the direction vector $\bar{g}=\left(\bar{g}^{x}, \bar{g}^{y}\right)$ where

$$
\begin{gathered}
\bar{g}^{x}=-\kappa x^{0}=-\frac{\beta_{x}}{\beta_{y}} x^{0} \text { and } \bar{g}^{y}=y^{0} . \text { Then, }(\bar{x}, \bar{y})=\left((1-\bar{\beta}) x^{0},(1+\bar{\beta}) y^{0}\right) \text { where } \\
\bar{\beta}=\vec{D}\left(x^{0}, y^{0} ; g^{x}=-\kappa x^{0}, g^{y}=y^{0}\right)
\end{gathered}
$$

is a conventional DDF with the direction of projection endogenously determined.

Figure 2 provides a graphical explanation of the proposed DDF. As in Figure 1, the point $P$ shows the observed input-output bundle $\left(x^{0}=9, y^{0}=4\right)$. The curve $O C$ is the graph of the production function $f(x)=2 \sqrt{x}$. The point $A(x=9, y=6)$ is the output oriented projection and $B(x=4, y=4)$ is the input oriented projection on to the frontier. The point $D\left(x^{*}=4, y^{*}=6\right)$ is above the curve $O C$ and is an infeasible point. As note before, the maximum output expansion factor is $\varphi^{*}=\frac{3}{2}$ and the minimum input contraction factor is $\theta^{*}=\frac{4}{9}$. We want to attain a feasible point on the frontier with minimum (downward) adjustment to $\varphi^{*}$ and (upward) adjustment to $\theta^{*}$. Now consider the direction vector $g$ defined by the point $E\left(x=x^{0}=9 ; y=-y^{0}=-4\right)$. We now move from the infeasible point $D$ along a line parallel to $O E$ and end up at the point $F$ on the $O C$ curve. At the point $F, x=\bar{x}=9\left(\theta^{*}+\delta\right)=4+9 \delta$ and $y=\bar{y}=4\left(\varphi^{*}-\delta\right)=6-4 \delta$. The reverse DDF $\delta$ is measured by the ratio $\frac{O G}{O E}$. In order to numerically evaluate $\delta$ we need to solve the equation

$$
\begin{aligned}
& f(\bar{x})=\bar{y} \\
& \Rightarrow 6-4 \delta=2 \sqrt{4+9 \delta} \\
& \Rightarrow 4+9 \delta=(3-2 \delta)^{2} \\
& \Rightarrow 4 \delta^{2}-21 \delta+5=0
\end{aligned}
$$

The two roots of the equation in (25) are 0.25 and 5. Clearly, because $F$ is a point on the frontier, $(\bar{x}, \bar{y}) \geq\left(x^{0}, y^{0}\right)$. This implies $\varphi^{*}-\delta \geq 1$ and $\theta^{*}+\delta \leq 1$. This leads to $\delta=0.25$. Hence, at the projection $F,(\bar{x}=6.25 ; \bar{y}=5)$. 
Last of all, we define the DDF for projecting the bundle $P$ to the selected point $F$ on the frontier. Using the values of $\left(\theta^{*}=\frac{4}{9}, \varphi^{*}=\frac{3}{2}, \delta=0.2536\right)$ we get $\left(\beta_{x}=0.306 ; \beta_{y}=0.25 ; \kappa=\frac{\beta_{x}}{\beta_{y}}=1.224\right)$ and

$\left(g^{x}=-\kappa x^{0}=-11 ; g^{y}=1\right)$. This direction vector is shown by the point $H$ and the corresponding DDF is

$$
\vec{D}\left(x^{0}, y^{0} ; g^{x}=-11, g^{y}=1\right)=\frac{O J}{O H}=0.25
$$

\subsection{Nonparametric Models}

In the exposition above, the production function defining the technology was presumed to be known. In reality, one would need to estimate the production function from observed input output data to measure the alternative Distance functions considered so far. The two popular estimation procedures are Stochastic Frontier Analysis (SFA) and Data Envelopment Analysis (DEA). In SFA, one starts with an explicit functional form of the production function (in the single output case) or the Distance function (in the multiple output case) incorporating a two-sided disturbance term to capture random noise alongside a one-sided disturbance reflecting technical inefficiency. In DEA, the nonparametric alternative based on mathematical programming, one avoids any explicit functional specification and only makes a number of fairly weak assumptions about the technology.

Starting from the data set consisting of $N$ pairs of observed input-output bundles $\left(x^{j}, y^{j}\right) ; j=1,2, \ldots, N$, in DEA one constructs an empirical estimate of the production possibility set assuming only that

- All observed input-output bundles are feasible;

- The production possibility set is convex;

- Inputs are freely disposable;

- Outputs are freely disposable.

The smallest convex set satisfying these assumptions is

$$
S=\left\{(x, y): x \geq \sum_{j} \lambda_{j} x^{j} ; y \leq \sum_{j} \lambda_{j} y^{j} ; \sum_{j} \lambda_{j}=1 ; \lambda_{j} \geq 0 ;(j=1,2, \ldots, N)\right\}
$$

The Output Distance function, which is the same as the output-oriented technical efficiency of the inputoutput bundle $\left(x^{0}, y^{0}\right)$ is 


$$
\begin{aligned}
& D^{y}\left(x^{0}, y^{0}\right)=\tau_{y}\left(x^{0}, y^{0}\right)=\frac{1}{\varphi^{*}} \text { where } \\
& \varphi^{*}=\max \varphi \\
& \sum_{j} \lambda_{j} y^{j} \geq \varphi y^{0} ; \\
& \sum_{j} \lambda_{j} x^{j} \leq x^{0} ; \\
& \sum_{j} \lambda_{j}=1 ; \lambda_{j} \geq 0,(j=1,2, \ldots, N) ; \varphi \text { unrestricted. }
\end{aligned}
$$

If $\left(x^{0}, y^{0}\right)$ is technically inefficient, $\varphi^{*}>1$ and its output-oriented efficient projection is $\left(x^{0}, \varphi^{*} y^{0}\right)$.

Similarly, the Input Distance function is

$D^{x}\left(x^{0}, y^{0}\right)=\frac{1}{\theta^{*}}$ where

$$
\begin{aligned}
& \theta^{*}=\tau_{x}\left(x^{0}, y^{0}\right)=\min \theta \\
& \sum_{j} \lambda_{j} y^{j} \geq y^{0} \\
& \sum_{j} \lambda_{j} x^{j} \leq \theta x^{0} \\
& \sum_{j} \lambda_{j}=1 ; \lambda_{j} \geq 0,(j=1,2, \ldots, N) ; \theta \text { unrestricted. }
\end{aligned}
$$

Again, if $\left(x^{0}, y^{0}\right)$ is technically inefficient, $\theta^{*}<1$ and its input-oriented efficient projection is $\left(\theta^{*} x^{0}, y^{0}\right)$.

Finally, the (conventional) Directional Distance Function can be obtained as

$$
\begin{aligned}
& \vec{D}\left(x^{0}, y^{0} ; g^{x}=-x^{0} \cdot g^{y}=y^{0}\right)=\beta^{*} \text { where } \\
& \beta^{*}=\max \beta \\
& \sum_{j} \lambda_{j} y^{j} \geq(1+\beta) y^{0} ; \\
& \sum_{j} \lambda_{j} x^{j} \leq(1-\beta) x^{0} ; \\
& \sum_{j} \lambda_{j}=1 ; \lambda_{j} \geq 0,(j=1,2, \ldots, N) ; \beta \text { unrestricted. }
\end{aligned}
$$


If $\left(x^{0}, y^{0}\right)$ is technically inefficient, $\beta^{*}>0$ and its Directional efficient projection is $\left(\left(1-\beta^{*}\right) x^{0},\left(1+\beta^{*}\right) y^{0}\right)$.

In (28)-(30), the relevant Distance functions were evaluated at the observed point $\left(x^{0}, y^{0}\right)$. Also, the objective was to scale the outputs upwards, or scale the inputs downwards, or some combination of both. By contrast, the Reverse Directional Distance function is evaluated at a hypothetical and infeasible point $\left(x^{*}, y^{*}\right)$ and the objective is to scale the inputs upwards and the outputs downwards to arrive at a feasible point. The relevant DEA LP problem is

$$
\begin{aligned}
& \overleftarrow{D}\left(x^{*}, y^{*} ; g^{x}=x^{0} \cdot g^{y}=-y^{0}\right)=\delta^{*} \text { where } \\
& \delta^{*}=\min \delta \\
& \sum_{j} \lambda_{j} y^{j} \geq\left(\varphi^{*}-\delta\right) y^{0} \Leftrightarrow \sum_{j} \lambda_{j} y^{j}+\delta y^{0} \geq y^{*} ; \\
& \sum_{j} \lambda_{j} x^{j} \leq\left(\theta^{*}+\delta\right) x^{0} \Leftrightarrow \sum_{j} \lambda_{j} x^{j}-\delta x^{0} \leq x^{*} ; \\
& \sum_{j} \lambda_{j}=1 ; \lambda_{j} \geq 0,(j=1,2, \ldots, N) ; \delta \text { unrestricted. }
\end{aligned}
$$

The optimal solution $\delta^{*}$ corresponds to the minimum adjustment that needs to be made to the target inputoutput pair $\left(x^{*}, y^{*}\right)$ so that the revised bundle $\left(\left(\theta^{*}+\delta^{*}\right) x^{0},\left(\varphi^{*}-\delta^{*}\right) y^{0}\right)$ becomes a feasible compromise solution.

The link between DEA and Multiple Objective Linear Programming (MOLP) has been explored in the Operations Research (OR)/Management Science (MS) literature by Athansssopoulos (1995, 1998), Li and Reeves (1999), Malkemohammadi et al. (2011), Izadikhah et al. (2014) among many others.

\section{Empirical Application}

\subsection{Data}

This study examines state-level data for the aggregate manufacturing sector in India over the years 201011 through 2013-145. The study covers 21 major manufacturing states in India, which together produced

\footnotetext{
${ }^{5}$ The data are reported by accounting year which runs from April $1^{\text {st }}$ to March $31^{\text {st }}$. Thus, the year 2013-14 refers to the period April 1, 2013 to March 31, 2014.
} 
$93.79 \%$ of the value of manufacturing output and used $94.43 \%$ of the value of energy consumed by the overall manufacturing sector in India in 2013-14. The state level data is obtained from the Annual Survey of Industries (ASI), Government of India, for the relevant years. The ASI covers all factories registered under the Factories Act of 1948.

We conceptualize a single-output, four- input production technology for the manufacturing sector. Output is measured by the gross value of manufacturing production in the state. The inputs include (i) capital, (ii) labor, (iii) energy, and (iv) materials. The capital input is measured as a stock by taking the value of fixed capital while labor is measured by the total number of persons employed. Energy and materials are measured by the expenditure on fuels and materials, respectively. All inputs and output are divided by the number of factories within the state so that we can examine and compare the efficiency of the 'typical' factory within each state. All values were deflated using appropriate annual wholesale price indexes reported by the Office of the Economic Advisor, Government of India, with 2004-05 as the base year. ${ }^{6}$

Next we need to address some modeling issues. In constructing the production frontier based on which efficiency is measured, we allow for variable returns to scale in the DEA models. In other words, we do not make any apriori assumptions regarding returns to scale of the 'typical' factory in the state. . Further, our maintained hypothesis is that technical change during our sample period was non-regressive. Hence, we create sequential frontiers rather than contemporaneous frontiers, for each year. In creating sequential frontiers we treat all past and current observations as feasible (Tulkens and Vanden Eeckaut, 1995). This has the additional advantage of increasing the number of observations for our frontier estimation which increases the degrees of freedom. To further increase the degrees of freedom in our analysis we used the data for the 21 states for the years 2004-05 to 2009-10 as initial values. Hence, we have a total of 210 observations for constructing our production frontier. When constructing the frontier for 2010-11 we start with 147 observations, and then successively enlarge our sample by including the observations from one more year as we evaluate the efficiency in the subsequent years. For our application with sequential frontiers we can modify the production possibility set in (25) to become

$$
S^{t}=\left\{(x, y): x \geq \sum_{j=1}^{N} \sum_{t=1}^{t} \lambda_{j}^{t} x_{j}^{t} ; y \leq \sum_{j=1}^{N} \sum_{t=1}^{t} \lambda_{j}^{t} y_{j}^{t} ; \sum_{j=1}^{N} \sum_{t=1}^{t} \lambda_{j}^{t}=1\right\},
$$

\footnotetext{
${ }^{6}$ For the output measure, the gross value of manufacturing production was deflated by the wholesale price index for manufactured products. For the inputs, the value of fixed capital was deflated by the wholesale price index of machinery and machine tools. The expenditure on fuels was deflated by the wholesale price index for fuel and power. Similarly, the expenditure on materials was deflated by the wholesale price index for non-food primary articles.
} 
when there are $\mathrm{N}$ units observed in each year and $t$ corresponds to the time period at which a unit is being evaluated. Conceptually, in this construction, when there is technical progress, the sequential frontier will shift out from year to year although any technical regress will be assimilated with measured inefficiency.

\subsection{The DEA Models}

In each of the DEA models in (28) through (31), the objective was to expand or contract all outputs or all inputs simultaneously by the same proportion. In that sense, these are all radial models. One may, however, wish to expand only selected outputs or contract selected inputs depending on the priorities of the analyst. In the present case, our objective is either to increase the output (in the output oriented model), or to reduce the use of only the energy input (in the input-oriented model), or to simultaneously increase output and reduce the energy input (in the conventional Directional model). Correspondingly, in the Reverse Directional model, we contract the output and increase energy to reach a feasible input-output bundle.

Specifically, the appropriate DEA formulations for this application will be:

\section{Output-oriented}

$$
\begin{aligned}
& \varphi^{*}=\max \varphi \\
& \sum_{j} \lambda_{j} y^{j} \geq \varphi y^{0} ; \quad \text { (Output) } \\
& \sum_{j} \lambda_{j} L_{j} \leq L_{0} ; \quad \text { (Labor) } \\
& \sum_{j} \lambda_{j} K_{j} \leq K_{0} ; \quad \text { (Capital) } \\
& \sum_{j} \lambda_{j} E_{j} \leq E_{0} ; \quad \text { (Energy) } \\
& \sum_{j} \lambda_{j} M_{j} \leq M_{0} ; \quad \text { (Materials) } \\
& \sum_{j} \lambda_{j}=1 ; \lambda_{j} \geq 0,(j=1,2, \ldots, N) ; \varphi \text { unrestricted. }
\end{aligned}
$$

\section{Energy-oriented}




$$
\begin{aligned}
& \theta^{*}=\min \theta \\
& \sum_{j} \lambda_{j} y^{j} \geq y^{0} ; \quad \text { (Output) } \\
& \sum_{j} \lambda_{j} L_{j} \leq L_{0} ; \quad \text { (Labor) } \\
& \sum_{j} \lambda_{j} K_{j} \leq K_{0} ; \quad \text { (Capital) } \\
& \sum_{j} \lambda_{j} E_{j} \leq \theta E_{0} ; \quad \text { (Energy) } \\
& \sum_{j} \lambda_{j} M_{j} \leq M_{0} ; \quad \text { (Materials) } \\
& \sum_{j} \lambda_{j}=1 ; \lambda_{j} \geq 0,(j=1,2, \ldots, N) ; \theta \text { unrestricted. }
\end{aligned}
$$

Directional

$$
\begin{aligned}
& \beta^{*}=\max \beta \\
& \sum_{j} \lambda_{j} y^{j} \geq(1+\beta) y^{0} ; \quad \text { (Output) } \\
& \sum_{j} \lambda_{j} L_{j} \leq L_{0} ; \quad \text { (Labor) } \\
& \sum_{j} \lambda_{j} K_{j} \leq K_{0} ; \quad \text { (Capital) } \\
& \sum_{j} \lambda_{j} E_{j} \leq(1-\beta) E_{0} ; \quad \text { (Energy) } \\
& \sum_{j} \lambda_{j} M_{j} \leq M_{0} ; \quad \text { (Materials) } \\
& \sum_{j} \lambda_{j}=1 ; \lambda_{j} \geq 0,(j=1,2, \ldots, N) ; \beta \text { unrestricted. }
\end{aligned}
$$

\section{$\underline{\text { Reverse Directional }}$}




$$
\begin{aligned}
& \delta^{*}=\min \delta \\
& \sum_{j} \lambda_{j} y^{j}+\delta y_{0} \geq y_{0}^{*} ; \quad \text { (Output) } \\
& \sum_{j} \lambda_{j} L_{j} \leq L_{0} ; \quad \text { (Labor) } \\
& \sum_{j} \lambda_{j} K_{j} \leq K_{0} ; \quad \text { (Capital) } \\
& \sum_{j} \lambda_{j} E_{j}-\delta E_{0} \leq E_{0}^{*} ; \quad \text { (Energy) } \\
& \sum_{j} \lambda_{j} M_{j} \leq M_{0} ; \quad \text { (Materials) } \\
& \sum_{j} \lambda_{j}=1 ; \lambda_{j} \geq 0,(j=1,2, \ldots, N) ; \delta \text { unrestricted. }
\end{aligned}
$$

\subsection{Results and Discussion}

Over our sample period total manufacturing output across the 21 states grew at an average annual rate of $4.5 \%$, fuels used grew at a rate of $1.7 \%$ and labor employed at a miniscule rate of $0.01 \%$. However, there was considerable variation across the states. While Bihar, Karnataka, Kerala, and Uttarakhand grew at an annual average rate of more than $8 \%$, states like Goa and Jharkhand actually showed a slight decline in their total output. The state of Andhra Pradesh also show a decline in total manufacturing output over our sample period due to the bifurcation of the state into Telangana and Andhra Pradhesh. The Annual Survey of Industries reports data separately for Telangana and Andhra Pradesh starting for the year 2012-13. However, since our analysis is based on per factory level analysis, the drastic reduction in the scale of the total manufacturing output of the state does not directly affect our intertemporal comparisons. Total fuels used in manufacturing declined in many states over our sample period. But the states of Assam and Jharkhand increased their fuel use by an average annual rate of more than $15 \%$ and $27 \%$, respectively.

Table 1 provides summary statistics for the output and inputs per factory across states for the four years of our study. The stock of fixed capital increased each year, showing evidence of capital accumulation. However, output per factory as well as the other inputs in the aggregate manufacturing sector fluctuated from year to year without any clear pattern. Comparing across states in terms of output per factory, the state of Goa had the largest average size of factory in the first three of the four years. On the other hand, Andhra Pradesh and Punjab had the smallest average size of factory. The output of the average factory in Goa was between 4.5 to 5 times the output of the average factory in Andhra Pradesh and Punjab during these three years. In the final year, the average factory in Uttarakhand produced the largest output compared to other states. 
The results from the efficiency analysis are presented in Tables 2-5. For each year, the results of the different efficiency models are presented in the same table to allow for ease of interpretation and comparison. For each state, the maximum possible increase in output given the level of inputs (measured by $\varphi^{*}$ ), were obtained using equation (33) and the results for each of the years are reported in Column (3) of tables 2 through 5 . The average $\varphi^{*}$ across the 21 states fluctuated from year to year. The average across the four years and 21 states was 1.046 implying that by eliminating technical inefficiency, on average it should be possible to increase output by $4.6 \%$ for the given levels of inputs. The typical factory in Andhra Pradesh, Bihar, Gujarat, and Punjab was efficient every year. In contrast, West Bengal, Madhya Pradesh and Uttar Pradesh were the most inefficient and it would be possible to increase their output on average by $18.6 \%, 16.7 \%$ and $12 \%$, respectively, over the four years.

Next, the energy input - oriented technical efficiency $\left(\theta^{*}\right)$ was obtained using equation (34). Column (4) of tables 2 through 5 presents the results for each year. We find that the average energy efficiency of the typical firm across states and years is 0.827 implying that given the levels of the other inputs the states could reduce the use of energy by $17.3 \%$ and still produce the given levels of output. Again Andhra Pradesh, Bihar, Gujarat, and Punjab were on the frontier every year and had a measured efficiency of 1 over the entire period. Chattisgarh, Madhya Pradesh, Odisha and West Bengal had energy efficiency of less than $60 \%$ on average over the four years.

The directional efficiency measure $\left(\beta^{*}\right)$ in equation (35) is reported in Column (5) of the tables $2-5$. Across states and years on average, a maximum proportional increase in output and conservation in energy of $3.8 \%$ is feasible given the available technology and levels of the other inputs. Andhra Pradesh, Bihar, Gujarat, and Punjab are the frontier states every year and so they are efficient by any measure of efficiency. Madhya Pradesh and West Bengal could increase their output and reduce energy use by $15 \%$ or more on average over the sample years. In case of Chattisgarh and Uttar Pradesh, on average over the four years it is possible to simultaneously increase output and reduce energy use by $8.4 \%$ and $9.1 \%$ respectively. The states of Goa, Kerala, and Tamil Nadu were efficient in three years of our sample by all the above three measures of efficiency.

During our sample period, Gujarat, Maharashtra, Tamil Nadu, Karnataka, and Uttar Pradesh are the five largest manufacturing states. ${ }^{7}$ We see a wide variation in the performance of these states. While Gujarat was efficient in all four years, Tamil Nadu was efficient in three of the four years and almost $100 \%$

\footnotetext{
${ }^{7}$ The state of Andhra Pradesh lost its size advantage after the bifurcation of the state.
} 
efficient in the other year. The annual average $\beta^{*}$ was $0.011,0.029$, and 0.091 for Maharashtra, Karnataka, and Uttar Pradesh, respectively.

The output-oriented and the energy input-oriented technical efficiency measures focus only on one goal each. Often a firm aspires to achieve both goals at the same time. While the $\beta$ measure takes into account that the objective of a firm may be to simultaneously increase output and reduce energy use, it does not enable us to directly understand the tradeoffs arising from the conflicting nature of the two objectives. One can conceive that one constituent or stakeholder of a firm is interested in one objective whereas another constituent or stakeholder is purely interested in the other. The two parties have to come to an optimal compromise solution where the two parties have to make the minimum sacrifice of their goal. The rate of concession in this conceived 'bargaining' framework based on equation (36) is reported by $\delta^{*}$ in Column (6) of tables 2 through 5. States that are on the frontier are already attaining the maximum output and minimum energy use and so no reconciliation is necessary between the two objectives. The average $\delta^{*}$ across the 21 states was $2.6 \%$ in 2010-11, 2.8\% in 2011-12, 2.2\% in 2012-13 and 3.1\% in 2013-14. Columns (7) and (8) respectively, of tables 2 through 5 report the adjusted increase in output and adjusted conservation in energy use (based on the reconciliation) that together represent a feasible target. On average across states, if output increase is the only goal, then a maximum of $4.7 \%$ increase in output is possible in 2013-14. In that same year, a maximum reduction in energy use of $20 \%$ on average is possible if that is the only goal. As mentioned earlier, these are not simultaneously achievable targets and some concession is required from both sides. After the 3.1\% concession from both goals, an average increase in output of $1.6 \%$ along with an average reduction in energy use by about $16.8 \%$ is possible. In contrast, using the traditional measure of $\beta^{*}$ suggests that output increase and energy reduction both be $4.1 \%$ on average.

While the above results are reported in percentage terms it is often insightful to know what this implies in terms of levels of the two goals. Table 6 reports the given output and energy input for each state for the year 2013-14 as well as the target output and energy levels based on the different models. ${ }^{8}$ If we focus on an average factory across our sample states, we can see how to interpret the results. The value of actual output 'per factory' in 2013-14 was Rupees 222.3 million at 2004-05 prices. If output oriented-efficiency alone is pursued, the output could be increased to Rupees 234 million. The value of actual energy used 'per factory' was Rupees 8.776 million. If energy reduction was the only goal then the energy used could be reduced to Rupees 6.817 million at a minimum. A combination of Rupees 234 million in output and Rupees 6.817 million energy used cannot be attained given the technology and levels of other inputs. The

\footnotetext{
${ }^{8}$ Note that the reported numbers in the tables are rounded off. Therefore, the values reported in Table 6 may not be exactly what is obtained from the figures reported in Table 5.
} 
traditional directional distance function approach suggests that a compromise optimal target would be to produce Rupees 232.4 million worth of output while using Rupees 7.922 million in energy used. In contrast, our proposed method suggests that the optimal target would be to produce Rupees 226.5 million of output using Rupees 7.091 million of energy input. What does this imply in terms of the tradeoffs between the two goals? The differences in output across the models have a direct impact on the overall GDP of the economy. On the other hand, the direct effect of reduction in energy is to reduce cost but the multitude of indirect effects must be measured using a more comprehensive economic modeling.

As shown in Table 7, the target based on the conventional DDF implies an increase in the output from the actual level, by Rupees 10.108 million coupled with reduction in energy input worth Rupees 0.854 million. By contrast, the target based on the reverse DDF would increase output from the actual level by Rupees 4.183 million but reduce energy cost by Rupees 1.685 million. A comparison of the two implies a Rupees 5.925 million sacrifice of output increase for additional Rupees 0.831 million of energy savings. On the face of it, the conventional DDF target would appear to be clearly a better deal. One must take into consideration the additional benefit from energy savings. For a broad calculation, suppose that all of the reduction in energy was in the form of reduced consumption of coal. At an inflation adjusted price of coal of Rupees 2117.7 per tonne ${ }^{9}$ this would be equivalent to a reduction of 392 tonnes of coal. At an estimated emission rate of 2.86 tonnes of $\mathrm{CO}_{2}$ per tonne of coal ${ }^{10}$, the implied reduction in $\mathrm{CO}_{2}$ would be $1,122.28$ tonne per factory. The resulting opportunity cost of $\mathrm{CO}_{2}$ reduction is reduction in achievable output by Rupees 528 per tonne. In light of the various health and environmental effects of greenhouse gas emissions, this may not be too high a price to pay for $\mathrm{CO}_{2}$ reduction. These numbers, however, are only suggestive and more accurate prediction is obtainable with more precise energy prices.

\section{Summary}

In this paper we introduce a reverse DDF as one possible approach to resolve the conflict between incompatible goals through a minimal adjustment applicable to all of the multiple objectives. In our empirical analysis we apply the proposed method to Indian manufacturing where increasing the output and conserving energy use are both highly important objectives. A comparison of the feasible targets obtained through the conventional and the reverse DDF yields an estimated tradeoff between output increase and $\mathrm{CO}_{2}$ reduction (due to energy conservation) along the frontier. One caveat of our illustration

\footnotetext{
${ }^{9}$ Authors' calculation based on Annual Survey of Industries Table 6A for 2013-14. Values were deflated using 2004-05 prices.

${ }^{10}$ See Hong, B. D., Slatick, E. R. (1994).
} 
is that using data for aggregate manufacturing masks the differences in manufacturing composition across states. Our proposed method will provide more meaningful policy implications when applied at the disaggregated industry level and using firm level data. 


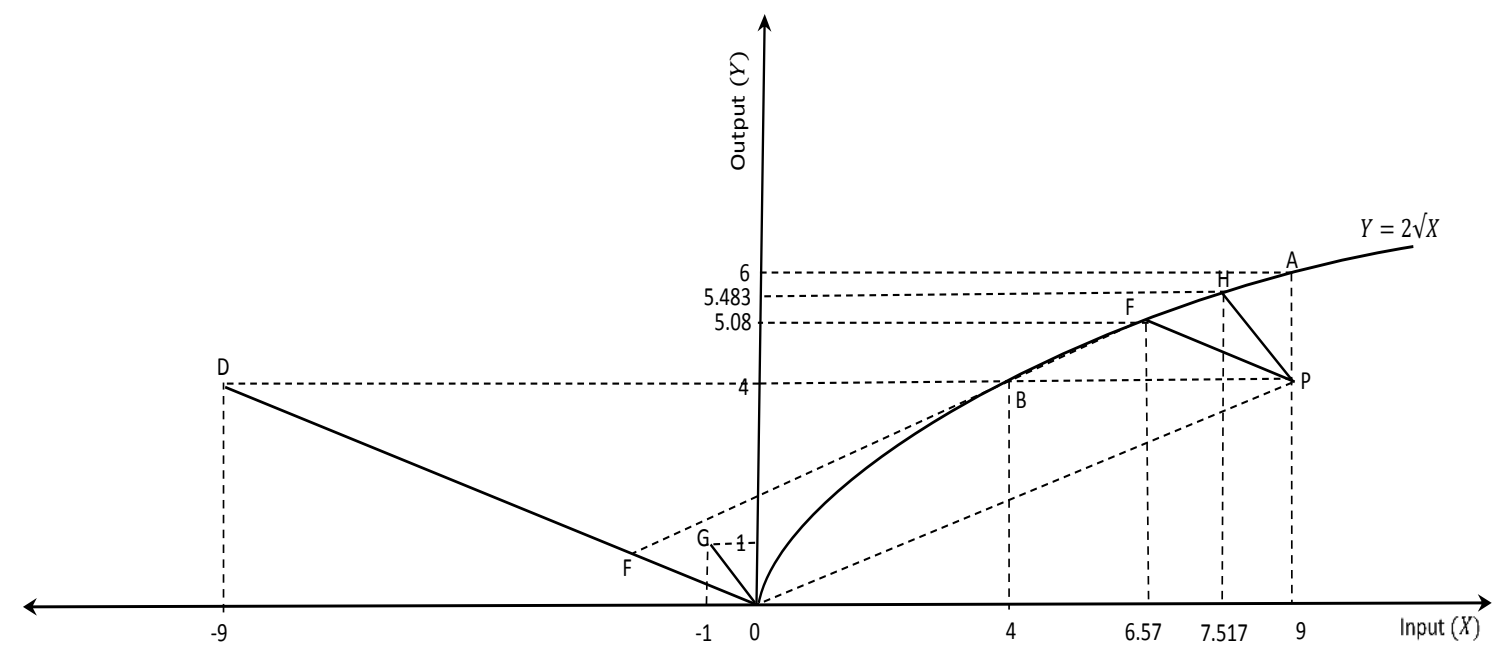

Figure 1: Input, Output and Directional Distance Functions 


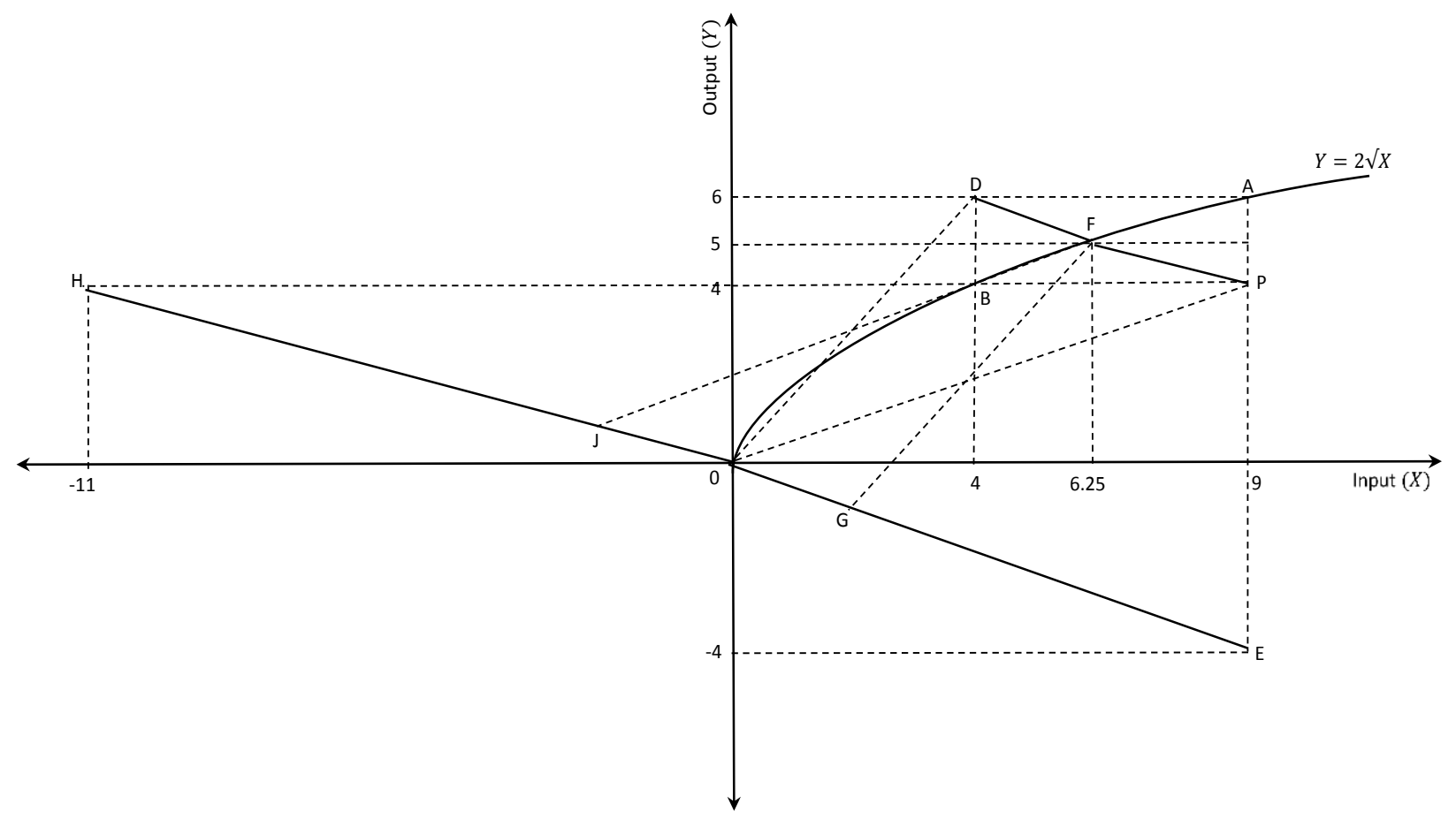

Figure 2: The Reverse and the Modified Directional Distance Functions 
Table 1: Summary of Output and Inputs

\begin{tabular}{|c|c|c|c|c|c|}
\hline & Output & Capital & Labor & Energy & Materials \\
\hline \multicolumn{6}{|l|}{$2010-11$} \\
\hline Mean & 204421 & 87501 & 69 & 9072 & 98304 \\
\hline Min & 89550 & 15504 & 38 & 3338 & 45179 \\
\hline Max & 428738 & 396482 & 112 & 28447 & 193057 \\
\hline St. Dev. & 90771 & 84581 & 19 & 6581 & 41097 \\
\hline \multicolumn{6}{|l|}{ 2011-12 } \\
\hline Mean & 225940 & 100932 & 72 & 9260 & 106652 \\
\hline Min & 100779 & 17592 & 39 & 3714 & 45079 \\
\hline Max & 513186 & 480374 & 120 & 31825 & 199506 \\
\hline St. Dev. & 103199 & 100985 & 22 & 7205 & 44079 \\
\hline \multicolumn{6}{|l|}{ 2012-13 } \\
\hline Mean & 218217 & 108824 & 66 & 9139 & 99765 \\
\hline Min & 91746 & 15105 & 33 & 3438 & 42719 \\
\hline Max & 417012 & 448316 & 115 & 29119 & 182576 \\
\hline St. Dev. & 98063 & 100012 & 20 & 6729 & 42733 \\
\hline \multicolumn{6}{|l|}{ 2013-14 } \\
\hline Mean & 222326 & 112577 & 68 & 8776 & 98753 \\
\hline Min & 98225 & 17809 & 33 & 1332 & 44444 \\
\hline Max & 399818 & 588603 & 132 & 25864 & 185685 \\
\hline St. Dev. & 94111 & 121477 & 23 & 6114 & 41598 \\
\hline
\end{tabular}

Note: The reported output and inputs are 'per factory'. Labor is reported in number of persons employed. Output and other inputs are reported in value in Rupees (INR) thousands. All values were deflated using appropriate wholesale price indexes with 2004-05 as the base year. 
Table 2: Comparison of Results across Models (2010-11)

\begin{tabular}{|c|c|c|c|c|c|c|c|}
\hline (1) & (2) & (3) & (4) & (5) & (6) & (7) & (8) \\
\hline $\mathbf{N}$ & State & $\varphi^{*}$ & $\boldsymbol{\theta}^{*}$ & $\boldsymbol{\beta}^{*}$ & $\boldsymbol{\delta}^{*}$ & $\varphi^{*}-\delta^{*}$ & $\boldsymbol{\theta}^{*}+\boldsymbol{\delta}^{*}$ \\
\hline 1 & AP & 1 & 1 & 0 & 0 & 1 & 1 \\
\hline 2 & AS & 1.025 & 0.953 & 0.020 & 0.012 & 1.013 & 0.965 \\
\hline 3 & BR & 1 & 1 & 0 & 0 & 1 & 1 \\
\hline 4 & CT & 1.113 & 0.391 & 0.107 & 0.074 & 1.039 & 0.465 \\
\hline 5 & GA & 1 & 1 & 0 & 0 & 1 & 1 \\
\hline 6 & GJ & 1 & 1 & 0 & 0 & 1 & 1 \\
\hline 7 & HR & 1.094 & 0.806 & 0.069 & 0.057 & 1.038 & 0.863 \\
\hline 8 & $\mathrm{HP}$ & 1 & 1 & 0 & 0 & 1 & 1 \\
\hline 9 & JK & 1 & 1 & 0 & 0 & 1 & 1 \\
\hline 10 & $\mathrm{JH}$ & 1 & 1 & 0 & 0 & 1 & 1 \\
\hline 11 & KA & 1.119 & 0.722 & 0.086 & 0.078 & 1.041 & 0.800 \\
\hline 12 & KL & 1 & 1 & 0 & 0 & 1 & 1 \\
\hline 13 & MP & 1.140 & 0.430 & 0.130 & 0.087 & 1.053 & 0.516 \\
\hline 14 & $\mathrm{MH}$ & 1 & 1 & 0 & 0 & 1 & 1 \\
\hline 15 & OR & 1.091 & 0.290 & 0.088 & 0.052 & 1.039 & 0.342 \\
\hline 16 & PB & 1 & 1 & 0 & 0 & 1 & 1 \\
\hline 17 & RJ & 1 & 1 & 0 & 0 & 1 & 1 \\
\hline 18 & TN & 1 & 1 & 0 & 0 & 1 & 1 \\
\hline 19 & UP & 1.044 & 0.756 & 0.040 & 0.034 & 1.010 & 0.790 \\
\hline 20 & UT & 1.165 & 0.674 & 0.139 & 0.080 & 1.085 & 0.754 \\
\hline 21 & WB & 1.134 & 0.586 & 0.125 & 0.075 & 1.059 & 0.661 \\
\hline & Average & 1.044 & 0.838 & 0.038 & 0.026 & 1.018 & 0.865 \\
\hline
\end{tabular}

Note: State codes are: AP = Andhra Pradesh; AS = Assam; BR = Bihar; CT = Chattisgarh;

GA = Goa; GJ = Gujarat; HR = Haryana; HP = Himachal Pradesh; JK = Jammu and Kashmir; JH = Jharkhand;

$\mathrm{KA}=$ Karnataka; $\mathrm{KL}=$ Kerala; $\mathrm{MP}=$ Madhya Pradesh; $\mathrm{MH}=$ Maharashtra;

$\mathrm{OR}=$ Odisha; $\mathrm{PB}=$ Punjab; RJ = Rajasthan; TN = Tamil Nadu; UP = Uttar Pradesh; UT = Uttarakhand;

$\mathrm{WB}=$ West Bengal. 
Table 3: Comparison of Results across Models (2011-12)

\begin{tabular}{|c|c|c|c|c|c|c|c|}
\hline (1) & (2) & (3) & (4) & (5) & (6) & (7) & (8) \\
\hline $\mathbf{N}$ & State & $\varphi^{*}$ & $\boldsymbol{\theta}^{*}$ & $\boldsymbol{\beta}^{*}$ & $\delta^{*}$ & $\varphi^{*}-\delta^{*}$ & $\boldsymbol{\theta}^{*}+\boldsymbol{\delta}^{*}$ \\
\hline 1 & AP & 1 & 1 & 0 & 0 & 1 & 1 \\
\hline 2 & AS & 1.164 & 0.862 & 0.104 & 0.047 & 1.116 & 0.909 \\
\hline 3 & BR & 1 & 1 & 0 & 0 & 1 & 1 \\
\hline 4 & CT & 1.155 & 0.345 & 0.148 & 0.075 & 1.080 & 0.420 \\
\hline 5 & GA & 1 & 1 & 0 & 0 & 1 & 1 \\
\hline 6 & GJ & 1 & 1 & 0 & 0 & 1 & 1 \\
\hline 7 & HR & 1.048 & 0.941 & 0.027 & 0.026 & 1.022 & 0.967 \\
\hline 8 & $\mathrm{HP}$ & 1.012 & 0.950 & 0.010 & 0.009 & 1.003 & 0.960 \\
\hline 9 & JK & 1 & 1 & 0 & 0 & 1 & 1 \\
\hline 10 & $\mathrm{JH}$ & 1.083 & 0.260 & 0.083 & 0.054 & 1.029 & 0.314 \\
\hline 11 & KA & 1 & 1 & 0 & 0 & 1 & 1 \\
\hline 12 & KL & 1 & 1 & 0 & 0 & 1 & 1 \\
\hline 13 & MP & 1.130 & 0.529 & 0.124 & 0.075 & 1.054 & 0.604 \\
\hline 14 & $\mathrm{MH}$ & 1.010 & 0.976 & 0.007 & 0.007 & 1.003 & 0.984 \\
\hline 15 & OR & 1.061 & 0.305 & 0.061 & 0.044 & 1.017 & 0.349 \\
\hline 16 & PB & 1 & 1 & 0 & 0 & 1 & 1 \\
\hline 17 & RJ & 1 & 1 & 0 & 0 & 1 & 1 \\
\hline 18 & $\mathrm{TN}$ & 1.002 & 0.993 & 0.002 & 0.002 & 1.001 & 0.995 \\
\hline 19 & UP & 1.198 & 0.591 & 0.143 & 0.118 & 1.081 & 0.709 \\
\hline 20 & UT & 1.026 & 0.958 & 0.016 & 0.016 & 1.010 & 0.974 \\
\hline 21 & WB & 1.270 & 0.519 & 0.207 & 0.118 & 1.152 & 0.637 \\
\hline & Averag & 1.055 & 0.820 & 0.044 & 0.028 & 1.027 & 0.849 \\
\hline
\end{tabular}

Note: State codes are: AP = Andhra Pradesh; AS = Assam; BR = Bihar; CT = Chattisgarh;

GA = Goa; GJ = Gujarat; HR = Haryana; HP = Himachal Pradesh; JK = Jammu and Kashmir; JH = Jharkhand;

$\mathrm{KA}=$ Karnataka; $\mathrm{KL}=$ Kerala; $\mathrm{MP}=$ Madhya Pradesh; $\mathrm{MH}=$ Maharashtra;

$\mathrm{OR}=$ Odisha; $\mathrm{PB}=$ Punjab; RJ = Rajasthan; TN = Tamil Nadu; UP = Uttar Pradesh; UT = Uttarakhand;

$\mathrm{WB}=$ West Bengal. 
Table 4: Comparison of Results across Models (2012-13)

\begin{tabular}{|c|c|c|c|c|c|c|c|}
\hline (1) & (2) & (3) & (4) & (5) & (6) & (7) & (8) \\
\hline $\mathbf{N}$ & State & $\varphi^{*}$ & $\boldsymbol{\theta}^{*}$ & $\boldsymbol{\beta}^{*}$ & $\delta^{*}$ & $\varphi^{*}-\delta^{*}$ & $\boldsymbol{\theta}^{*}+\boldsymbol{\delta}^{*}$ \\
\hline 1 & AP & 1 & 1 & 0 & 0 & 1 & 1 \\
\hline 2 & $\mathrm{AS}$ & 1 & 1 & 0 & 0 & 1 & 1 \\
\hline 3 & BR & 1 & 1 & 0 & 0 & 1 & 1 \\
\hline 4 & $\mathrm{CT}$ & 1.074 & 0.400 & 0.074 & 0.040 & 1.034 & 0.440 \\
\hline 5 & GA & 1 & 1 & 0 & 0 & 1 & 1 \\
\hline 6 & GJ & 1 & 1 & 0 & 0 & 1 & 1 \\
\hline 7 & HR & 1.016 & 0.972 & 0.010 & 0.010 & 1.006 & 0.982 \\
\hline 8 & HP & 1.112 & 0.738 & 0.078 & 0.078 & 1.034 & 0.817 \\
\hline 9 & $\mathrm{JK}$ & 1.010 & 0.976 & 0.007 & 0.007 & 1.003 & 0.983 \\
\hline 10 & $\mathrm{JH}$ & 1.003 & 0.549 & 0.003 & 0.003 & 1 & 0.553 \\
\hline 11 & KA & 1 & 1 & 0 & 0 & 1 & 1 \\
\hline 12 & KL & 1 & 1 & 0 & 0 & 1 & 1 \\
\hline 13 & MP & 1.172 & 0.514 & 0.172 & 0.097 & 1.074 & 0.611 \\
\hline 14 & $\mathrm{MH}$ & 1 & 1 & 0 & 0 & 1 & 1 \\
\hline 15 & OR & 1.009 & 0.628 & 0.009 & 0.008 & 1.001 & 0.635 \\
\hline 16 & $\mathrm{~PB}$ & 1 & 1 & 0 & 0 & 1 & 1 \\
\hline 17 & RJ & 1.001 & 0.787 & 0.001 & 0 & 1 & 0.788 \\
\hline 18 & $\mathrm{TN}$ & 1 & 1 & 0 & 0 & 1 & 1 \\
\hline 19 & UP & 1.121 & 0.727 & 0.087 & 0.081 & 1.040 & 0.808 \\
\hline 20 & UT & 1.014 & 0.979 & 0.008 & 0.008 & 1.005 & 0.987 \\
\hline 21 & WB & 1.219 & 0.518 & 0.172 & 0.125 & 1.094 & 0.643 \\
\hline & Averag & 1.036 & 0.847 & 0.030 & 0.022 & 1.014 & 0.869 \\
\hline
\end{tabular}

Note: State codes are: AP = Andhra Pradesh; AS = Assam; BR = Bihar; CT = Chattisgarh;

GA = Goa; GJ = Gujarat; HR = Haryana; HP = Himachal Pradesh; JK = Jammu and Kashmir; JH = Jharkhand;

$\mathrm{KA}=$ Karnataka $\mathrm{KL}=$ Kerala MP = Madhya Pradesh; $\mathrm{MH}=$ Maharashtra;

$\mathrm{OR}=$ Odisha; $\mathrm{PB}=$ Punjab; RJ = Rajasthan; TN = Tamil Nadu; UP = Uttar Pradesh; UT = Uttarakhand;

$\mathrm{WB}=$ West Bengal. 
Table 5: Comparison of Results across Models (2013-14)

\begin{tabular}{|c|c|c|c|c|c|c|c|}
\hline (1) & (2) & (3) & (4) & (5) & (6) & (7) & (8) \\
\hline $\mathbf{N}$ & State & $\varphi^{*}$ & $\boldsymbol{\theta}^{*}$ & $\boldsymbol{\beta}^{*}$ & $\delta^{*}$ & $\varphi^{*}-\delta^{*}$ & $\boldsymbol{\theta}^{*}+\boldsymbol{\delta}^{*}$ \\
\hline 1 & AP & 1 & 1 & 0 & 0 & 1 & 1 \\
\hline 2 & AS & 1.003 & 0.983 & 0.003 & 0.003 & 1 & 0.986 \\
\hline 3 & BR & 1 & 1 & 0 & 0 & 1 & 1 \\
\hline 4 & $\mathrm{CT}$ & 1.007 & 0.480 & 0.007 & 0.006 & 1.001 & 0.485 \\
\hline 5 & GA & 1.055 & 0.848 & 0.041 & 0.040 & 1.015 & 0.888 \\
\hline 6 & GJ & 1 & 1 & 0 & 0 & 1 & 1 \\
\hline 7 & HR & 1.164 & 0.465 & 0.164 & 0.079 & 1.085 & 0.544 \\
\hline 8 & HP & 1.066 & 0.741 & 0.053 & 0.051 & 1.015 & 0.792 \\
\hline 9 & JK & 1.055 & 0.742 & 0.047 & 0.044 & 1.011 & 0.786 \\
\hline 10 & $\mathrm{JH}$ & 1 & 1 & 0 & 0 & 1 & 1 \\
\hline 11 & KA & 1.042 & 0.909 & 0.029 & 0.029 & 1.013 & 0.938 \\
\hline 12 & KL & 1.059 & 0.520 & 0.056 & 0.048 & 1.011 & 0.568 \\
\hline 13 & MP & 1.228 & 0.502 & 0.201 & 0.122 & 1.107 & 0.623 \\
\hline 14 & $\mathrm{MH}$ & 1.045 & 0.813 & 0.037 & 0.036 & 1.009 & 0.850 \\
\hline 15 & OR & 1.008 & 0.848 & 0.008 & 0.008 & 1 & 0.856 \\
\hline 16 & $\mathrm{~PB}$ & 1 & 1 & 0 & 0 & 1 & 1 \\
\hline 17 & RJ & 1.021 & 0.802 & 0.020 & 0.018 & 1.004 & 0.820 \\
\hline 18 & TN & 1 & 1 & 0 & 0 & 1 & 1 \\
\hline 19 & UP & 1.115 & 0.565 & 0.093 & 0.089 & 1.026 & 0.654 \\
\hline 20 & UT & 1 & 1 & 0 & 0 & 1 & 1 \\
\hline 21 & WB & 1.123 & 0.586 & 0.097 & 0.089 & 1.035 & 0.675 \\
\hline & Averag & 1.047 & 0.800 & 0.041 & 0.031 & 1.016 & 0.832 \\
\hline
\end{tabular}

Note: State codes are: AP = Andhra Pradesh; AS = Assam; BR = Bihar; CT = Chattisgarh;

GA = Goa; GJ = Gujarat; HR = Haryana; HP = Himachal Pradesh; JK = Jammu and Kashmir; JH = Jharkhand;

$\mathrm{KA}=$ Karnataka; $\mathrm{KL}=$ Kerala; $\mathrm{MP}=$ Madhya Pradesh; $\mathrm{MH}=$ Maharashtra;

$\mathrm{OR}=$ Odisha; $\mathrm{PB}=$ Punjab; RJ = Rajasthan; TN = Tamil Nadu; UP = Uttar Pradesh; UT = Uttarakhand;

$\mathrm{WB}=$ West Bengal. 
Table 6: Actual and Target Levels of Output and Energy Input across Models (2013-14)

\begin{tabular}{|c|c|c|c|c|c|c|c|c|c|}
\hline $\mathbf{N}$ & State & $\mathbf{Y}^{0}$ & $\mathbf{Y} *\left(\varphi^{*}\right)$ & $\mathbf{Y} *\left(\varphi^{*}-\delta^{*}\right)$ & $\mathbf{Y} *\left(\boldsymbol{\beta}^{*}\right)$ & $\mathbf{E}^{\mathbf{0}}$ & $\mathbf{E}^{*}\left(\boldsymbol{\theta}^{*}\right)$ & $\mathbf{E}^{*}\left(\boldsymbol{\theta}^{*}+\boldsymbol{\delta}^{*}\right)$ & $\mathbf{E}^{*}\left(\boldsymbol{\beta}^{*}\right)$ \\
\hline 1 & AP & 110670 & 110670 & 110670 & 110670 & 4474 & 4474 & 4474 & 4474 \\
\hline 2 & $\mathrm{AS}$ & 108462 & 108806 & 108516 & 108753 & 4626 & 4547 & 4559 & 4614 \\
\hline 3 & BR & 107107 & 107107 & 107107 & 107107 & 1332 & 1332 & 1332 & 1332 \\
\hline 4 & CT & 277003 & 278950 & 277363 & 278950 & 17135 & 8221 & 8319 & 8751 \\
\hline 5 & GA & 362111 & 382165 & 367618 & 376858 & 10537 & 8937 & 9360 & 10107 \\
\hline 6 & GJ & 356266 & 356266 & 356266 & 356266 & 8487 & 8487 & 8487 & 8487 \\
\hline 7 & HR & 320898 & 373406 & 348036 & 373406 & 14883 & 6919 & 8095 & 10935 \\
\hline 8 & HP & 234944 & 250405 & 238357 & 247343 & 6951 & 5151 & 5508 & 6584 \\
\hline 9 & $\mathrm{JK}$ & 164136 & 173094 & 165938 & 171815 & 3935 & 2921 & 3093 & 3751 \\
\hline 10 & $\mathrm{JH}$ & 265577 & 265577 & 265577 & 265577 & 25864 & 25864 & 25864 & 25864 \\
\hline 11 & $\mathrm{KA}$ & 243250 & 253497 & 246496 & 250252 & 5258 & 4780 & 4931 & 5106 \\
\hline 12 & $\mathrm{KL}$ & 121692 & 128832 & 123004 & 128522 & 3851 & 2004 & 2189 & 3635 \\
\hline 13 & MP & 281602 & 345829 & 311610 & 338241 & 11907 & 5974 & 7421 & 9512 \\
\hline 14 & $\mathrm{MH}$ & 242400 & 253345 & 244597 & 251353 & 7295 & 5934 & 6197 & 7026 \\
\hline 15 & OR & 298622 & 301058 & 298746 & 300934 & 20108 & 17047 & 17203 & 19953 \\
\hline 16 & $\mathrm{~PB}$ & 98225 & 98225 & 98225 & 98225 & 4843 & 4843 & 4843 & 4843 \\
\hline 17 & $\mathrm{RJ}$ & 161202 & 164637 & 161780 & 164484 & 7272 & 5832 & 5961 & 7124 \\
\hline 18 & $\mathrm{TN}$ & 119941 & 119941 & 119941 & 119941 & 3937 & 3937 & 3937 & 3937 \\
\hline 19 & UP & 188317 & 209978 & 193276 & 205922 & 6552 & 3702 & 4283 & 5940 \\
\hline 20 & UT & 399818 & 399818 & 399818 & 399818 & 8295 & 8295 & 8295 & 8295 \\
\hline 21 & WB & 206607 & 232080 & 213759 & 226680 & 6756 & 3959 & 4558 & 6100 \\
\hline & Average & 222326 & 233985 & 226509 & 232434 & 8776 & 6817 & 7091 & 7922 \\
\hline
\end{tabular}

Note 1: Output and Energy input are reported in value in Rupees (INR) thousands at 2004-05 prices.

Note 2: State codes are: $\mathrm{AP}=$ Andhra Pradesh; $\mathrm{AS}=$ Assam; $\mathrm{BR}=\mathrm{Bihar} ; \mathrm{CT}=$ Chattisgarh;

GA = Goa; GJ = Gujarat; HR = Haryana; HP = Himachal Pradesh; JK = Jammu and Kashmir; JH = Jharkhand;

KA = Karnataka KL = Kerala; MP = Madhya Pradesh; MH = Maharashtra;

OR = Odisha PB = Punjab; RJ = Rajasthan; TN = Tamil Nadu; UP = Uttar Pradesh; UT = Uttarakhand; WB = West Bengal. 
Table 7: Comparison of Alternative Targets and Implied Tradeoffs

\begin{tabular}{|c|c|c|c|c|c|c|}
\hline & Actual & DDF & $\begin{array}{l}\text { Reverse } \\
\text { DDF }\end{array}$ & $\Delta \mathrm{DDF}$ & $\begin{array}{l}\Delta \text { Reverse } \\
\text { DDF }\end{array}$ & Tradeoffs \\
\hline $\mathbf{Y}$ & 222326 & 232434 & 226509 & 10108 & 4183 & 5925 \\
\hline $\mathbf{E}$ & 8776 & 7922 & 7091 & 854 & 1685 & 831 \\
\hline
\end{tabular}

Note: Output and Energy input are reported in value in Rupees (INR) thousands at 2004-05 prices. 


\section{References}

Aparacio, J., Pastor, J. T., Ray, S. C. (2013) An Overall Measure of Technical Efficiency at the Firm and at the Industry Level: The 'Lost Profit on Outlay', European Journal of Operational Research, $226,154-162$.

Athanassopoulis, A. (1995) Goal Programming and Data Envelopment Analysis (GoDEA) for Target Based Multi-Level Planning: Allocating Central Grants to the Greek Local Authorities, European Journal of Operational Research, 87, 35-50.

Athanassopoulis, A. (1998) Decision Support for Target-Based Resource Allocation of Public Services in Multiunit and Multilevel Systems, Management Science, 39, 10, 1261-1264.

Chambers, R. G., Chung, Y., and Färe, R. (1996) Benefit and Distance Functions, Journal of Economic Theory, 70, 407-419.

Ebinger, C. K. (2016) India's Energy and Climate Policy: Can India Meet the Challenge of Industrialization and Climate Change? Brookings Energy Security and Climate Initiative, Policy Brief 16-01.

Hong, B. D., Slatick, E. R. (1994) Carbon Dioxide Emission Factors for Coal, U.S. Energy Information Administration, Quarterly Coal Report,January-April 1994, DOE/EIA-0121(94/Q1), Washington, DC, 1-8.

International Energy Agency (2015) India Energy Outlook, World Energy Outlook, Special Report.

Izadikhah, M., Roostaee, R., Lotfi, F. H. (2014) Using Goal Programming Method to Solve DEA Problems with Value Judgments, Yugoslav Journal of Operations Research, 24, 2, 267-282.

Li, X. B., Reeves, G. R. (1999) A Multiple Criteria Approach to Data Envelopment Analysis, European Journal of Operational Research, 115, 507-517.

Malekmohammadi, N., Lotfi, F. H., Jaafar, A. B. (2011) Target Setting in Data Envelopment Analysis Using MOLP, Applied Mathematical Modeling, 35, 328-338.

Mandal, S. K. (2010) Measuring Environmental Efficiency and Cost of Pollution Abatement: An Application of Directional Distance Function to Indian Cement Industry, South Asian Journal of 
Management, 17, 3, 23-37.

Mandal, S. K., Madheswaran, S. (2010) Environmental Efficiency of the Indian Cement Industry: An Interstate Analysis, Energy Policy, 38, 1108-1118.

Mukherjee, K. (2010) Measuring Energy Efficiency in the Context of a Developing Economy: The Case of Indian Manufacturing, European Journal of Operational Research, 201, 933-941.

Shephard, R. W. (1970) Theory of Cost and Production Functions Princeton: Princeton University Press.

Tulkens, H., Vanden Eeckaut, P. (1995) Non-frontier Measures of Efficiency, Progress, and Regress for Time Series Data, International Journal of Production Economics, 39, 83-97. 